\title{
Tumor Findings Sequence Number
}

National Cancer Institute

\section{Source}

National Cancer Institute. Tumor Findings Sequence Number. NCI Thesaurus. Code C119938.

An identifier that describes the relative position of tumor findings data within a series. 